\title{
Article \\ Design and Development of Magnesium-Based Suture Anchor for Rotator Cuff Repair Using Finite Element Analysis and In Vitro Testing
}

\author{
Ting-Yu Su ${ }^{1}$, Hao-Yuan Tang ${ }^{1}$, Jason Shian-Ching Jang ${ }^{2, *} \mathbb{C}$, Chih-Hwa Chen ${ }^{1,3,4, * \mathbb{C}}$ and Hsiang-Ho Chen $5,6, * \mathbb{D}$ \\ 1 School of Biomedical Engineering, College of Biomedical Engineering, Taipei Medical University, \\ Taipei 11031, Taiwan; b812106015@tmu.edu.tw (T.-Y.S.); b812105034@tmu.edu.tw (H.-Y.T.) \\ 2 Department of Mechanical Engineering, Institute of Materials Science and Engineering, National Central \\ University, Taoyuan 32001, Taiwan \\ 3 Department of Orthopedics, Shuang Ho Hospital, Taipei Medical University, Taipei 23561, Taiwan \\ 4 Bone and Joint Research Center, Department of Orthopedics, Taipei Medical University Hospital, \\ School of Medicine, College of Medicine, Taipei Medical University, Taipei 11031, Taiwan \\ 5 Center for Biomedical Engineering, Graduate Institute of Biomedical Engineering, College of Engineering, \\ Chang Gung University, Taoyuan 33302, Taiwan \\ 6 Bone and Joint Research Center, Department of Orthopedic Surgery, Chang Gung Memorial Hospital Linkou \\ Branch, Taoyuan 333, Taiwan \\ * Correspondence: jscjang@ncu.edu.tw (J.S.-C.J.); chihhwachen@gmail.com (C.-H.C.); \\ hchen@mail.cgu.edu.tw (H.-H.C.); Tel.: +886-3-4267-397 (J.S.-C.J.); +886-2-2736-1661 (C.-H.C.); \\ +886-2-211-8800 (H.-H.C.); Fax: +886-3-211-8700 (H.-H.C.)
}

check for
updates

Citation: Su, T.-Y.; Tang, H.-Y.; Jang, J.S.-C.; Chen, C.-H.; Chen, H.-H.

Design and Development of

Magnesium-Based Suture Anchor for Rotator Cuff Repair Using Finite

Element Analysis and In Vitro Testing. Appl. Sci. 2021, 11, 9602. https:// doi.org/10.3390/app11209602

Academic Editors: Raffaella Pecci, Ilaria Campioni, Antonio Scarano and Francesca Mangione

Received: 19 August 2021

Accepted: 12 October 2021

Published: 15 October 2021

Publisher's Note: MDPI stays neutral with regard to jurisdictional claims in published maps and institutional affiliations.

Copyright: (c) 2021 by the authors. Licensee MDPI, Basel, Switzerland. This article is an open access article distributed under the terms and conditions of the Creative Commons Attribution (CC BY) license (https:/ / creativecommons.org/licenses/by/ $4.0 /)$.
Featured Application: Collaboration between material science and mechanical engineering can be used to drive improvements in medical implants and applications. Using a magnesium-based alloy, we developed a new suture anchor design with four distinctive parameters, and we optimized its structural performance. Our findings indicated that the Young's modulus of the newly developed magnesium-based alloy must be lower than that of industrial magnesium alloy for enhanced clinical results.

Abstract: A suture anchor is a medical device commonly used in rotator cuff repair surgery to attach tendons to the greater tuberosity of the humerus. Patient- and device-related factors, such as structural designs and poor bone density, can cause unsatisfactory clinical results. In this study, a new suture anchor design with four distinctive parameters was proposed, and the structural performance was optimized in a full factorial experimental design using finite element analysis. Two types of bone blocks - normal and osteoporotic bone-which received screw implants, were simulated to investigate the parametrical effects on various bone qualities. The prescribed motion at a constant removal velocity was used to evaluate the pullout strength. The von Mises criterion was employed in a force control simulation for topology optimization. Moreover, mechanical tests guided by ASTM-F543-17 were conducted for validation. This paper demonstrates the comprehensive process for developing a suture anchor with sufficient mechanical integrity for clinical use and clarifies the contributions of each distinctive design parameter in this application.

Keywords: suture anchor; bone implant; finite element analysis; mechanical testing

\section{Introduction}

Suture anchors have been prevalently used in orthopedic surgery for rotator cuff repair, which involves the fixation of tendons to the lesser or greater tuberosity (Figure 1) [1-5]. Beneath the bone surface, the cyclic loading of anchor removal during daily activities induces microfractures of the bone at the screw-bone interface, which is the principal mechanism in mechanical failure [6,7]. Under such circumstances, some patient- and 
design-related factors associated with mechanical fixation strength against pullout force may aggravate chronic and symptomatic progression of rotator cuff tear [8-10]. Therefore, the relationships between design-related factors, including structures and materials, and mechanical strength against pullout loading are the primary considerations of studies on suture anchor design.

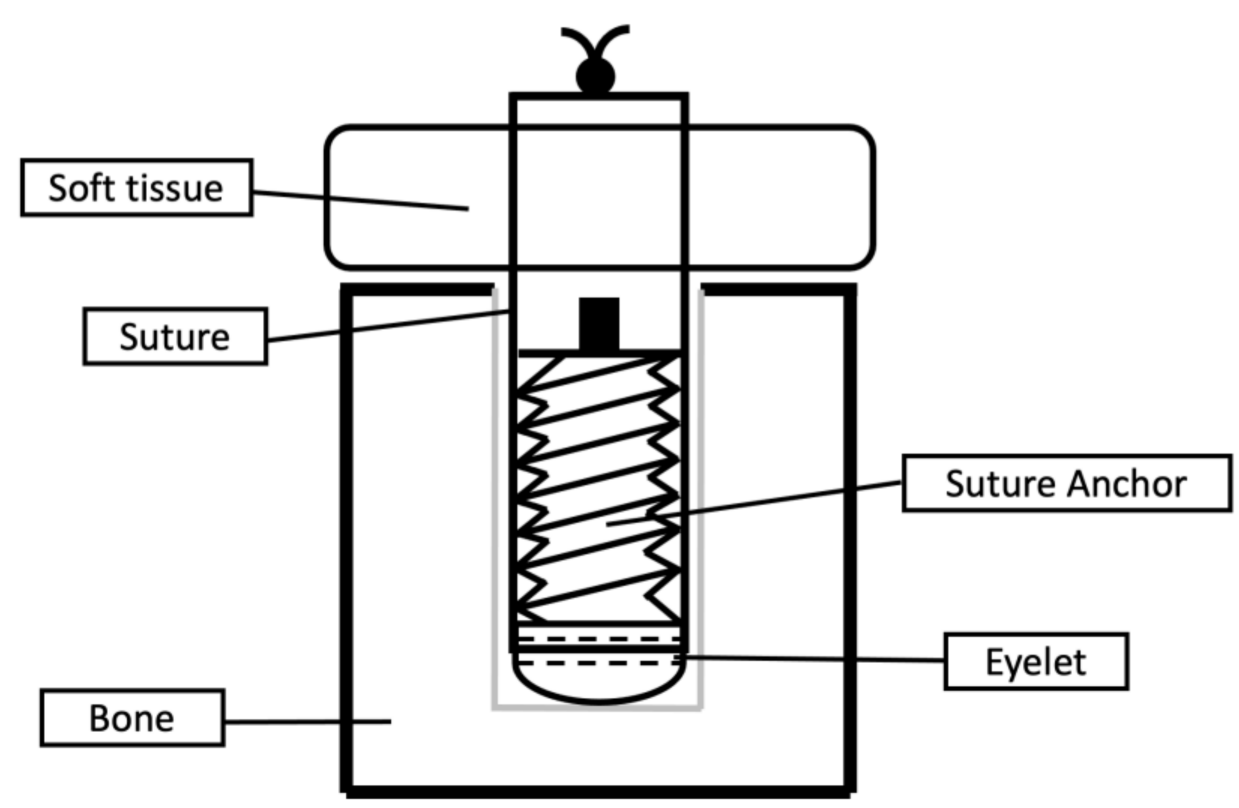

Figure 1. Illustration of the use of a suture anchor for soft tissue repair. The suture anchor is screwed into a predrilled hole in the bone to stabilize the suture. The suture can then penetrate through the soft tissue and be tied in order to fix the soft tissue to the bone.

To validate the primary stability of a suture anchor's fixation, studies have used finite element analysis (FEA) for diverse purposes, including the mechanical analysis of soft tissue and bone implants design [11,12]. With FEA, designers are able to predict whether their designs are suitable for clinical use and further revise the design if they discover any problems. After the suture anchor is manufactured, the axial pullout test, following the standard operating procedure of ASTM-F543, executed during the removal of bone screws from their insertion site in bone blocks is a standard approach for quantifying the primary stability of designs $[13,14]$. Several studies have not only used the testing procedure of ASTM F543 for design analysis, but also used it to study the local deformation of bone structure during a screw pullout test [15]. In addition, biomechanical experiments, such as those involving the use of a universal force moment sensor or robotic evaluation system for cadaveric and animal bones can provide predictive results under physiological conditions [16]. Several studies on orthopedic and dental implants have revealed various structural parameters that influence the primary stability of screw topology, including pitch, contact area, thread shapes, and cylindrical part dimensions [17-19].

Materials are also crucial considerations in the mechanical and biochemical aspects of bone screw applications. Studies have extensively investigated the designs of suture anchors and conducted structural analyses using common biomaterials, such as stainless steel, titanium alloys, and biodegradable polymers [20-23]. Magnesium (Mg)-based materials hold considerable promise for use with bone tissue because of their analogous strength to that of bone, strong bone integration effects, and high biocompatibility; such materials have thus received increased attention in bone implant applications [24-26]. However, suture anchors using such Mg-based materials are few, and the mechanical stability of such distinctive materials is under-investigated.

To assess the biomechanical performance of a new suture anchor design based on an Mg-based alloy, we employed a four-factor full factorial design method (Figure 2). By 
assessing the effects of various combinations of distinctive parameters through FEA and ASTM F-543 tests, we developed a novel suture anchor design that exhibits mechanical strength levels and provides a durable stress distribution for more favorable clinical results.

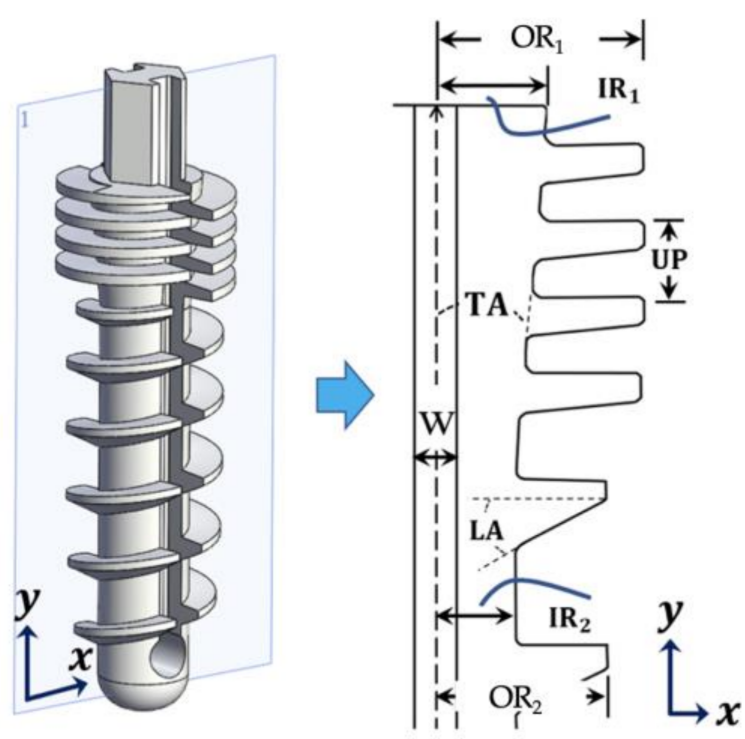

Figure 2. Dimensional characteristics of the proposed suture anchor design. Four design parameters, tapered angle (TA), upper thread pitch (UP), groove width (W), and lower thread angle (LA) are indicated. Outer (OR) and internal radii (IR) are also shown.

\section{Materials and Methods}

\subsection{FEA of Screw Structure}

Our framework included two FEA simulations: displacement and force control. The prescribed motion was simulated in displacement control for validation, and the results were compared with those obtained in mechanical testing. Force control using the von Mises criterion was performed to investigate the contributions of design parameters and determine the optimal design for the pullout tests. All FEA simulations were conducted using the implicit method to address quasistatic problems during pullout.

Our geometrical models comprised a suture anchor and a polyurethane (PU) block corresponding to the configuration in ASTM F-543. Preprocessing of the FE models was performed using ANSYS/LS-Dyna (ANSYS Inc., Canonsburg, PA, USA). Twenty-four computer-aided design models were manually meshed using FE preprocessing software.

Ten-node tetrahedral elements were applied to the FE models (Figure 3a). To accurately investigate the effects of contact areas, for the test block, a fine mesh $(0.22 \mathrm{~mm})$ was applied to the screw-bone interface; a coarse mesh $(0.7-3.5 \mathrm{~mm})$ was used in more distant regions of the test foam. For the suture anchor, the size of the elements in the whole structure was consistent with that of the elements in the contact areas. The convergence test was conducted first. The variance of the maximum von Mises stress value between consecutive groups was less than $3 \%$. Moreover, when the size of suture anchor meshes was smaller than $0.22 \mathrm{~mm}$, the number of elements was 102,000, and the number of elements in the PU blocks was 118,000, we observed that the quality of the elements was high [11]. Accordingly, the number of elements in the testing model was determined to be approximately 220,000 . 


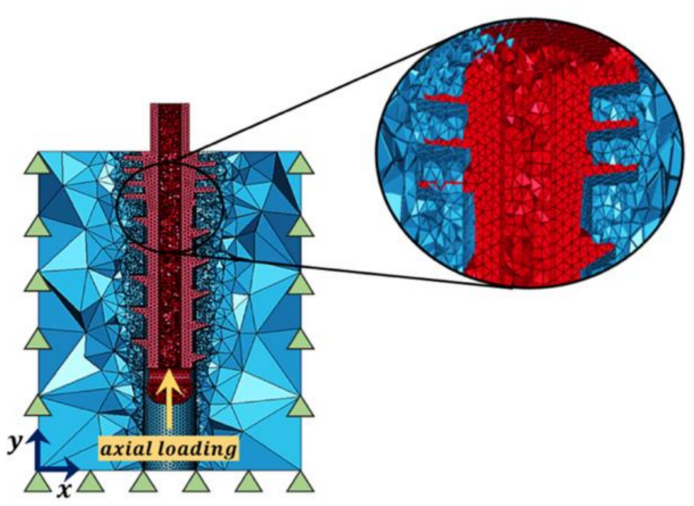

(a)

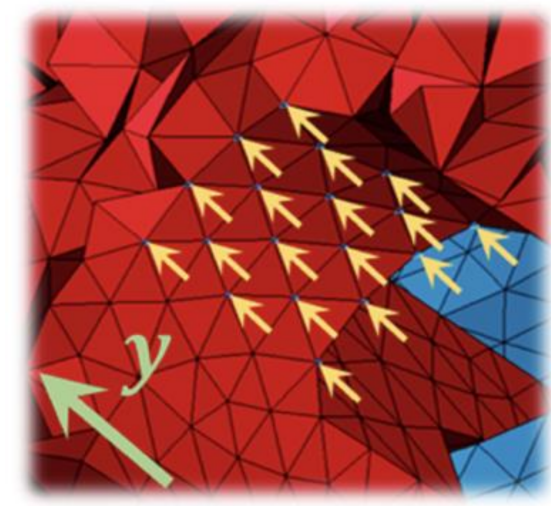

(b)

Figure 3. FE Mesh of a suture anchor and a PU (bone) block. (a) Entire model and its local mesh; (b) contact forces of the interface and their direction.

The suture anchor was set to move along the longitudinal axis by referencing the displacement curve in the prescribed motion form for displacement control. Moreover, a pullout force, which was vertical to the insertion plane, was loaded for force control. All peripheral nodes of the test blocks were constrained in all directions, and the suture anchor nodes were free in the axial direction. Contact between the screw-block interface was set to a penalty-based surface-to-surface contact, with a friction coefficient of 0.2. Different types of material properties were derived from the literature and applied to the models [27]. Previously determined linear elastic properties of a common magnesium alloy (AM 1004T61) were applied to the suture anchors (Table 1) [28]. For the PU blocks, the properties of a piecewise linear elastic material were applied, in addition to the application of the mechanical properties of two types of bone, namely a normal bone and an osteoporotic one [29]. These properties were compared with those of solid foam (solid rigid polyurethane foam, Sawbones, USA) measuring 20 pounds per cubic foot (PCF; representing normal bone) and $10 \mathrm{PCF}$ (representing osteoporotic bone) for validation.

Table 1. Mechanical properties of materials in the FEA models.

\begin{tabular}{cccccc}
\hline & $\begin{array}{c}\text { Density } \\
\left(\mathbf{K g} / \mathbf{m}^{\mathbf{3}}\right)\end{array}$ & $\begin{array}{c}\text { Young's } \\
\text { Modulus (MPa) }\end{array}$ & $\begin{array}{c}\text { Poisson's } \\
\text { Ratio }\end{array}$ & $\begin{array}{c}\text { Yield } \\
\text { Strength }\end{array}$ & $\begin{array}{c}\text { Friction } \\
\text { Coefficient }\end{array}$ \\
\hline Am1004-T61 & 1830 & 44,770 & 0.3 & & \\
PU foam 20 PCF & 320 & 210 & 0.3 & 8.4 & 0.2 \\
PU foam 10 PCF & 160 & 58 & 0.3 & 2.2 & 0.2 \\
\hline
\end{tabular}

In the displacement-controlled simulation, the pullout strength of the suture anchor was evaluated to assess the stability of the design under a single pullout procedure, and the results were compared with the mechanical testing results for validation. A constant velocity of $0.1 \mathrm{~mm} / \mathrm{s}$ was applied to the bottom nodes of the suture anchor. Pullout strength was defined as the maximum value of the reaction force at the bone-screw interface.

In the force-controlled simulation, the stress distribution of the suture anchor, which could provide information on material failure, was investigated by applying an upward loading to the bottom of the suture loop (Figure $3 b$ ). The stress distribution and maximum von Mises stress were estimated to evaluate the structural factors and determine the optimal design. This study did not consider the cyclic loading of anchor removal.

\subsection{Mechanical Tests Based on ASTM F-543}

Mechanical tests were executed in accordance with ASTM F543-17, which provides standards for testing methods of metallic medical bone screws. Magnesium-based alloy was 
used as the material of the prototypes. The prototypes were manufactured using computer numerical control (CNC) machining (Figure 4). For these tests, metallic bone screws implanted into the test blocks were subjected to an axial tensile force until failure or removal, and their mechanical properties were measured; among the test blocks, those measuring 10 PCF represented osteoporotic samples, and those measuring 20 PCF represented normal bone samples (Figure 5). An MTS 858 Bionix test system (MTS systems, Eden Prairie, MN, USA) was used to perform the tests. The test procedures can be summarized as follows: (1) Drill a pilot hole of a specified size at the center of the top surface of the test block. (2) Insert the suture anchor until complete penetration into the block. (3) Hold the block using the clamp, and attach the suture to the loading fixture. (4) Apply a tensile load to the test specimen at a rate of $5 \mathrm{~mm} / \mathrm{min}$ until the screw fails or releases from the test block. (5) Concurrently, record the loading versus displacement profile for comparison (Figures 6 and 7). Six samples were tested in both the 10 and 20 PCF groups.

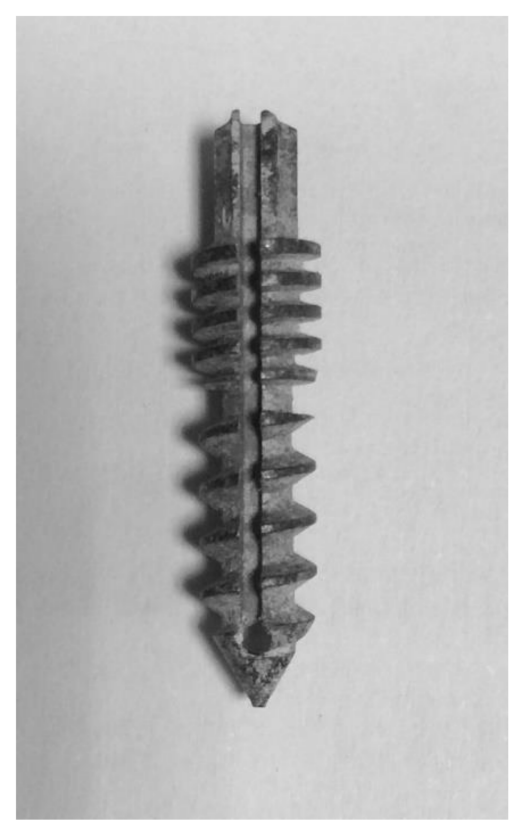

Figure 4. Prototype of the suture anchor manufactured using CNC machining.

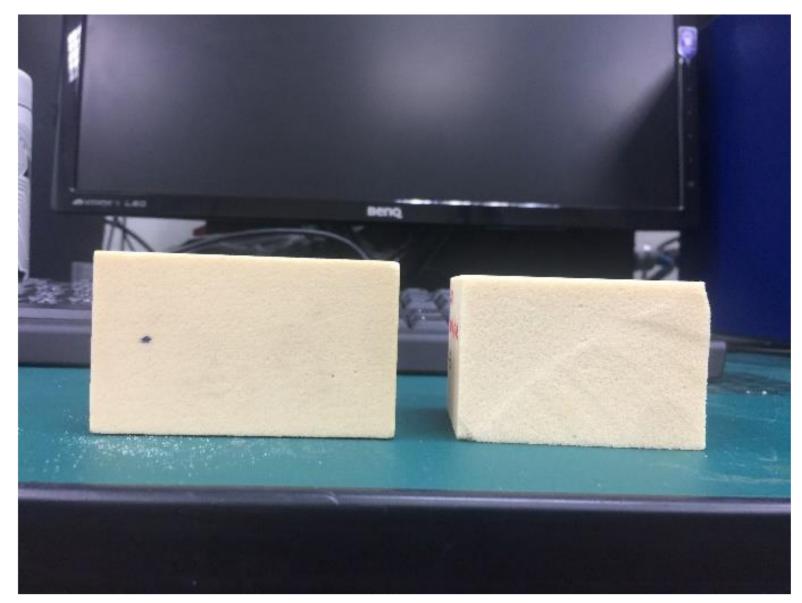

Figure 5. Two types of test blocks: 10 PCF (right) and 20 PCF (left). 


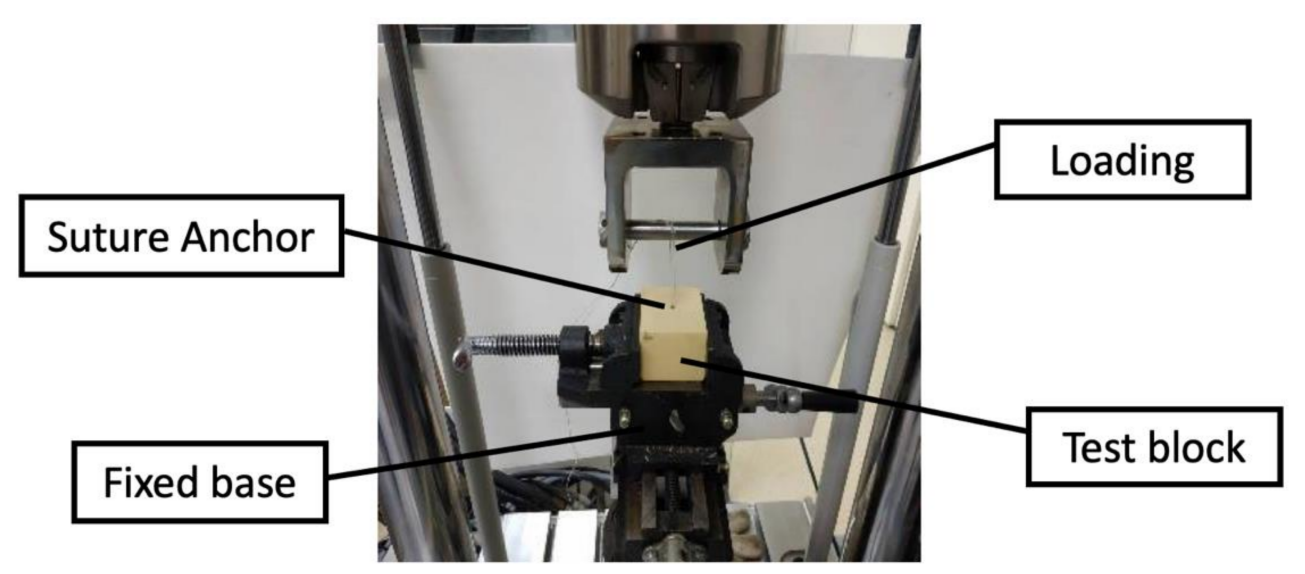

Figure 6. Setup of the pullout test. The test block was stabilized by the clamp, which was fixed to the base. The suture anchor with the suture applied on was inserted into the test block. The suture was then fixed to the testing machine to provide the axial force for pullout.

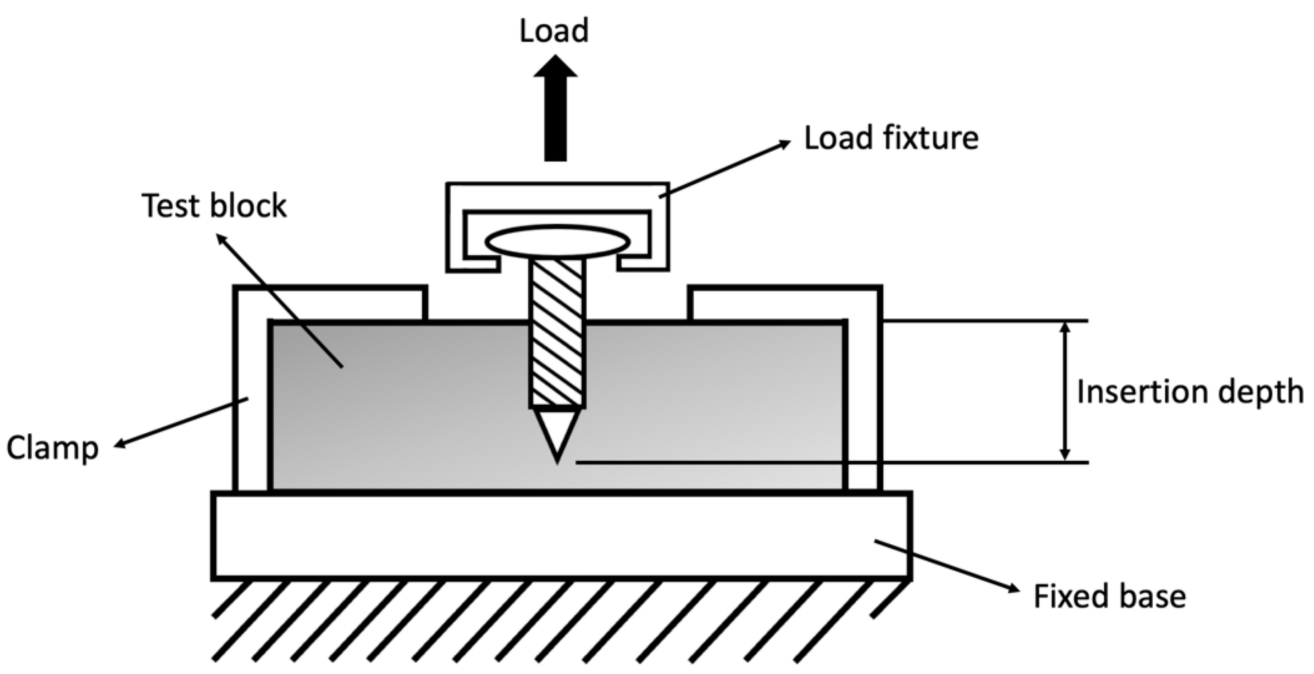

Figure 7. Test apparatus for pullout test recommended by the ASTM F543 protocol [30].

\section{Results}

\subsection{Estimation of the Pullout Strength of Suture Anchors}

In the normal (20 PCF) group, the highest maximum reaction force for each suture anchor, which we defined as pullout strength in the mechanical tests, was observed for the LA1UP2W1TA3 anchor $(\sim 1170 \mathrm{~N})$. The anchor with the lowest pullout strength was LA1UP2W2TA3 (1115 N). In the osteoporosis (10 PCF) group, anchors with the highest and lowest pullout force were LA1UP2W1TA1 (310 N) and LA2UP1W2TA3 (296 N), respectively. Thus, the pullout strength of all suture anchors in the normal group (20 PCF) was higher than that in the osteoporotic group (10 PCF) (Figure 8). The average pullout strength value of each parameters in both groups were estimated and compared (Tables 2 and 3 ).

Table 2. Comparison of average pullout strength of four different design factors in 20 PCF.

\begin{tabular}{cccc}
\hline & Small & Medium & Large \\
\hline Lower Thread Angle (LA) & $1147 \mathrm{~N}$ & & $1140 \mathrm{~N}$ \\
Upper Thread Pitch (UP) & $1146 \mathrm{~N}$ & & $1140 \mathrm{~N}$ \\
Groove Width (W) & $1155 \mathrm{~N}$ & & $1130 \mathrm{~N}$ \\
Tapered Angle (TA) & $1146 \mathrm{~N}$ & $1135 \mathrm{~N}$ & $1140 \mathrm{~N}$ \\
\hline
\end{tabular}


Table 3. Comparison of average pullout strength of four different design factors in 10 PCF.

\begin{tabular}{cccc}
\hline & Small & Medium & Large \\
\hline Lower Thread Angle (LA) & $305 \mathrm{~N}$ & & $302 \mathrm{~N}$ \\
Upper Thread Pitch (UP) & $305 \mathrm{~N}$ & $303 \mathrm{~N}$ \\
Groove Width (W) & $308 \mathrm{~N}$ & & $300 \mathrm{~N}$ \\
Tapered Angle (TA) & $305 \mathrm{~N}$ & $300 \mathrm{~N}$ & $302 \mathrm{~N}$ \\
\hline
\end{tabular}

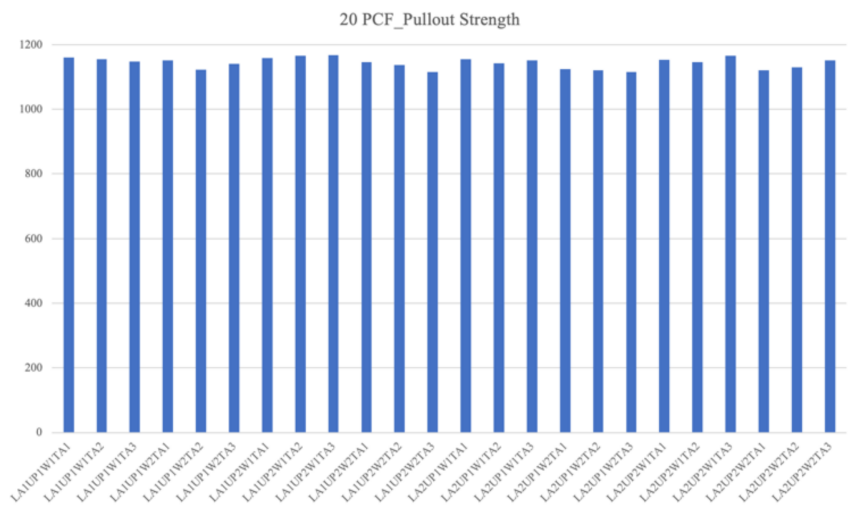

(a)

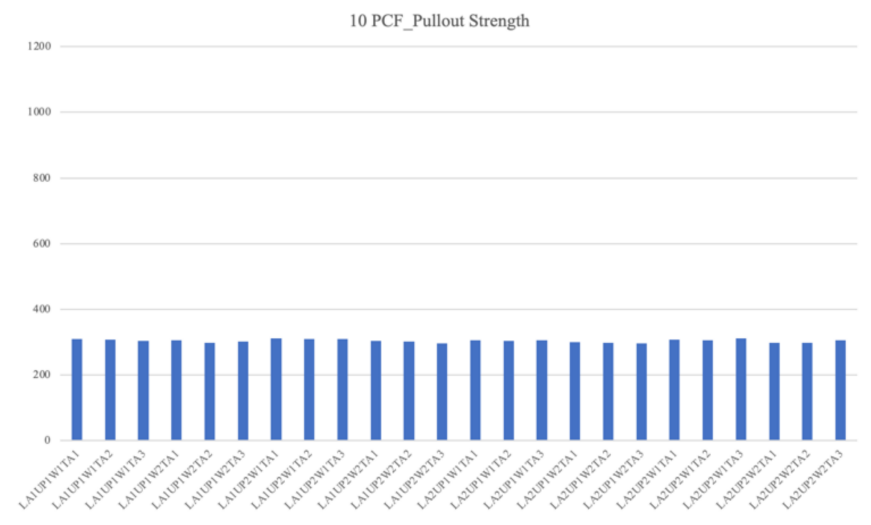

(b)

Figure 8. Comparison of pullout strength of 24 groups in (a) 20 PCF and (b) 10 PCF.

\subsection{Distribution of Stress on Anchors}

The areas with the highest von Mises stress were identified, which indicated the areas with the greatest likelihood of anchor breakage during the pullout movement. In the normal (20 PCF) group, the lowest and highest values were observed for LA2UP2W2TA1 (115 MPa) and LA1UP2W2TA3 (200 MPa), respectively. In the osteoporosis (10 PCF) group, LA2UP2W1TA3 (32 MPa) LA1UP1W1TA2 (70 MPa) exhibited the lowest and highest values, respectively (Figure 9). The average stress value on anchors of each parameters in both groups were estimated and compared (Tables 4 and 5).

Table 4. Comparison of average stress on anchor of four different design factors in 20 PCF.

\begin{tabular}{cccc}
\hline & Small & Medium & Large \\
\hline Lower Thread Angle (LA) & $165 \mathrm{MPa}$ & & $143 \mathrm{MPa}$ \\
Upper Thread Pitch (UP) & $144 \mathrm{MPa}$ & & $165 \mathrm{MPa}$ \\
Groove Width (W) & $146 \mathrm{MPa}$ & & $162 \mathrm{MPa}$ \\
Tapered Angle (TA) & $153 \mathrm{MPa}$ & $157 \mathrm{MPa}$ & $151 \mathrm{MPa}$ \\
\hline
\end{tabular}

Table 5. Comparison of average stress on anchor of four different design factors in 10 PCF.

\begin{tabular}{cccc}
\hline & Small & Medium & Large \\
\hline Lower Thread Angle (LA) & $56 \mathrm{MPa}$ & & $46 \mathrm{MPa}$ \\
Upper Thread Pitch (UP) & $50 \mathrm{MPa}$ & & $55 \mathrm{MPa}$ \\
Groove Width (W) & $50 \mathrm{MPa}$ & & $54 \mathrm{MPa}$ \\
Tapered Angle (TA) & $53 \mathrm{MPa}$ & $49 \mathrm{MPa}$ & $51 \mathrm{MPa}$ \\
\hline
\end{tabular}




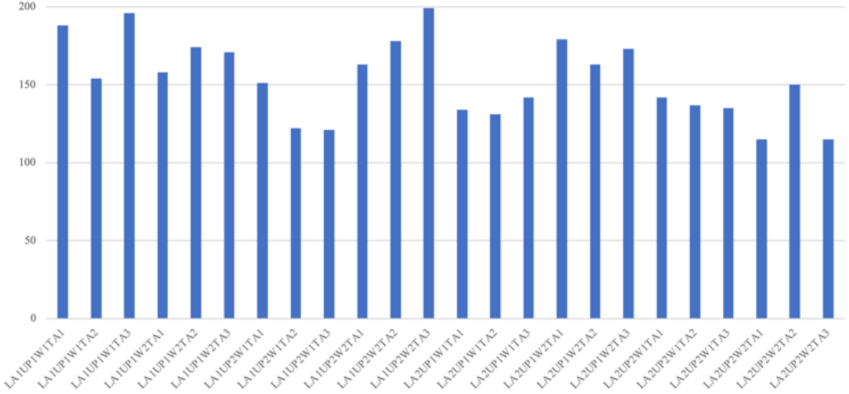

(a)

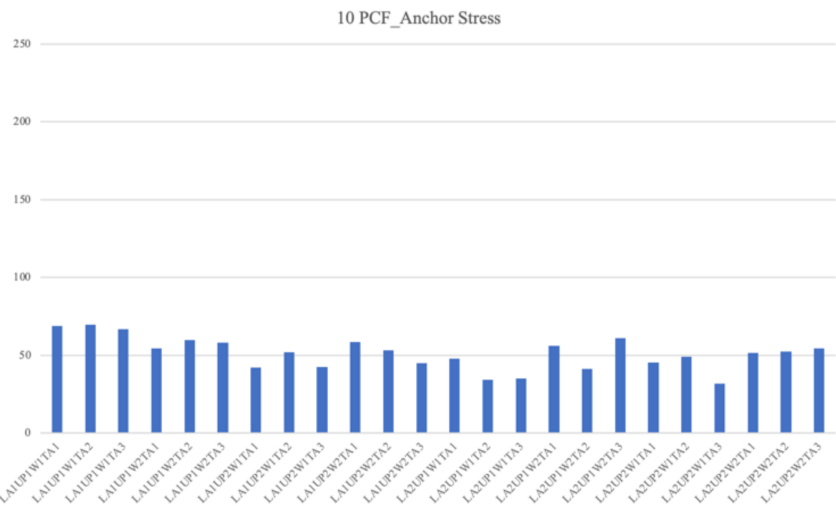

(b)

Figure 9. Comparison of the stress on anchor of 24 groups in (a) 20 PCF and (b) 10 PCF.

\subsection{Distribution of Stress on the First Layer of a Test Block}

To analyze the effect on a test block during pullout, the mean von Mises stress in the first layer was estimated. In the normal (20 PCF) group, the maximum and minimum von Mises stress values in the test block were observed for LA1UP2W2TA3 (2.6 MPa) and LA2UP2W1TA1 (2.2 MPa), respectively. In the osteoporosis (10 PCF) group, the corresponding maximum and minimum values were noted for LA2UP1W1TA3 (1.0 MPa) and LA2UP2W1TA3 $(0.7 \mathrm{MPa})$, respectively (Figure 10). The average stress value on the first layer of test block of each parameters in both groups were estimated and compared (Tables 6 and 7).

Table 6. Comparison of average stress on the first layer of test block of four different design factors in 20 PCF.

\begin{tabular}{cccc}
\hline & Small & Medium & Large \\
\hline Lower Thread Angle (LA) & $2.5 \mathrm{MPa}$ & & $2.3 \mathrm{MPa}$ \\
Upper Thread Pitch (UP) & $2.3 \mathrm{MPa}$ & & $2.5 \mathrm{MPa}$ \\
Groove Width (W) & $2.3 \mathrm{MPa}$ & & $2.4 \mathrm{MPa}$ \\
Tapered Angle (TA) & $2.3 \mathrm{MPa}$ & $2.4 \mathrm{MPa}$ & $2.4 \mathrm{MPa}$ \\
\hline
\end{tabular}

Table 7. Comparison of average stress on the first layer of test block of four different design factors in 10 PCF.

\begin{tabular}{cccc}
\hline & Small & Medium & Large \\
\hline Lower Thread Angle (LA) & $0.83 \mathrm{MPa}$ & & $0.85 \mathrm{MPa}$ \\
Upper Thread Pitch (UP) & $0.82 \mathrm{MPa}$ & & $0.87 \mathrm{MPa}$ \\
Groove Width (W) & $0.81 \mathrm{MPa}$ & & $0.88 \mathrm{MPa}$ \\
Tapered Angle (TA) & $0.84 \mathrm{MPa}$ & $0.85 \mathrm{MPa}$ & $0.85 \mathrm{MPa}$ \\
\hline
\end{tabular}




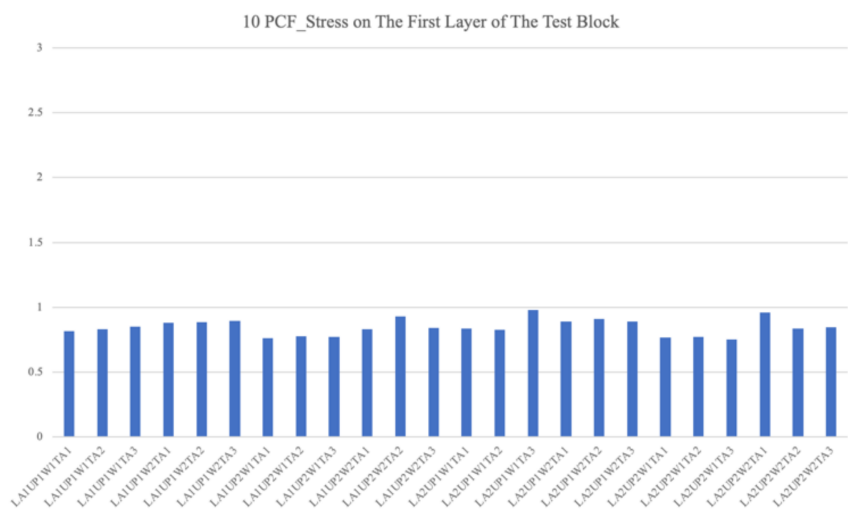

(a)

(b)

Figure 10. Comparison of the stress on the first layer of test block of 24 groups in (a) 20 PCF and (b) 10 PCF.

\subsection{Distribution of Stress on the Second Layer of the Reverse Buttress Part of the Test Block}

Because two threads were included in this design, the stress of the threads was analyzed to prevent early failure. In the normal (20 PCF) group, the maximum and minimum von Mises stress values in the second layer of the reverse buttress part on the test block were observed for LA1UP2W1TA2 (5.9 MPa) and LA1UP1W2TA2 (5.7 MPa), respectively. In the osteoporosis (10 PCF) group, the corresponding highest and lowest values were noted for LA2UP1W1TA2 and LA2UP1W1TA3 ( 1.7 MPa) and LA2UP2W2TA2 $(\sim 1.6 \mathrm{MPa})$, respectively (Figure 11). The average stress value of that part of each parameters in both groups were estimated and compared (Tables 8 and 9).

Table 8. Comparison of average stress on the second layer of the reverse buttress part of test block of four different design factors in 20 PCF.

\begin{tabular}{cccc}
\hline & Small & Medium & Large \\
\hline Lower Thread Angle (LA) & $5.8 \mathrm{MPa}$ & & $5.7 \mathrm{MPa}$ \\
Upper Thread Pitch (UP) & $5.7 \mathrm{MPa}$ & & $5.8 \mathrm{MPa}$ \\
Groove Width (W) & $5.7 \mathrm{MPa}$ & $5.8 \mathrm{MPa}$ \\
Tapered Angle (TA) & $5.7 \mathrm{MPa}$ & $5.7 \mathrm{MPa}$ & $5.8 \mathrm{MPa}$ \\
\hline
\end{tabular}

Table 9. Comparison of average stress on the second layer of the reverse buttress part of test block of four different design factors in 10 PCF.

\begin{tabular}{cccc}
\hline & Small & Medium & Large \\
\hline Lower Thread Angle (LA) & $1.6 \mathrm{MPa}$ & & $1.7 \mathrm{MPa}$ \\
Upper Thread Pitch (UP) & $1.6 \mathrm{MPa}$ & & $1.7 \mathrm{MPa}$ \\
Groove Width (W) & $1.7 \mathrm{MPa}$ & & $1.6 \mathrm{MPa}$ \\
Tapered Angle (TA) & $1.6 \mathrm{MPa}$ & $1.7 \mathrm{MPa}$ & $1.7 \mathrm{MPa}$ \\
\hline
\end{tabular}


20 PCF Stress on The Second Layer of the Reverse Buttress Part of The Test Block

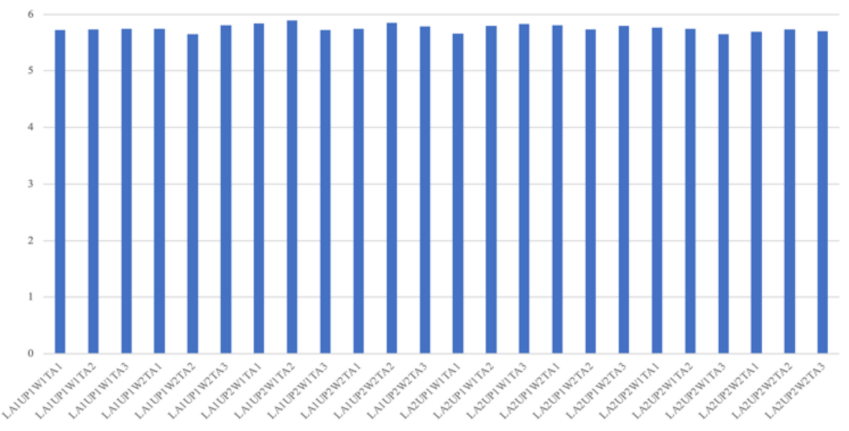

(a)
10 PCF Stress on The Second Layer of the Reverse Buttress Part of The Test Block

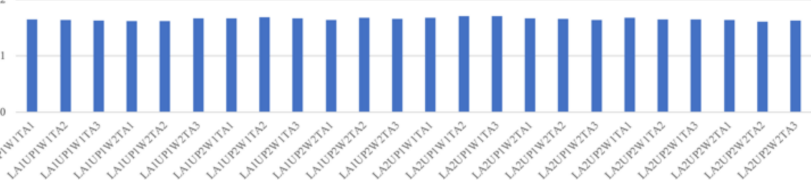

(b)

Figure 11. Comparison of the stress on the second layer of the reverse buttress part of test block of 24 groups in (a) 20 PCF and (b) 10 PCF.

\subsection{Pullout Strength of Suture Anchors in Mechanical Testing}

According to results of FEA simulation, the design with the parameter LA1UP2W1TA3, with a larger tapered angle (TA), a smaller upper thread pitch (UP), a smaller groove width (W), and a smaller lower thread angle (LA), had the highest pullout strength in normal bone blocks. With an outer radius of $2.5 \mathrm{~mm}$, the prototype of this optimal anchor was chosen to be manufactured and tested in the material testing machine. In the normal (20 PCF) and osteoporosis (10 PCF) groups, the average pullout strength levels for the six samples were $409 \pm 16$ and $104 \pm 6 \mathrm{~N}$, respectively (Figure 12).

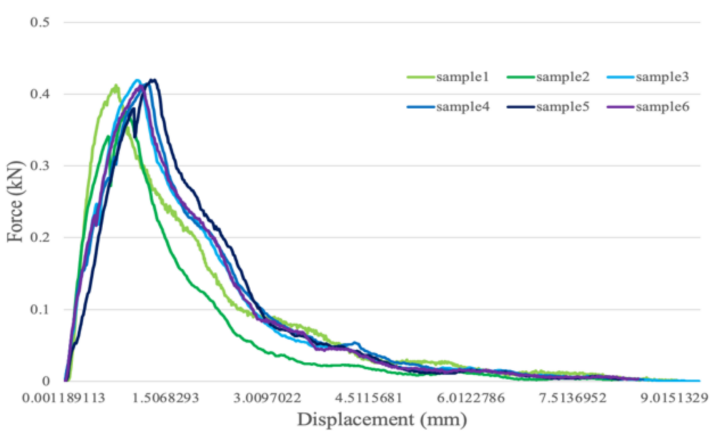

(a)

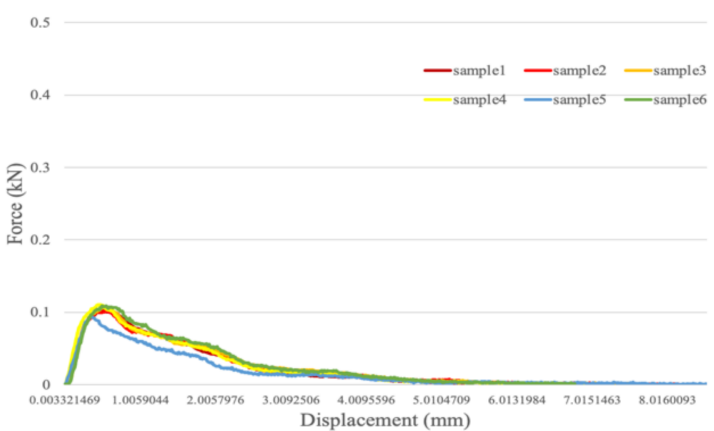

(b)

Figure 12. Force-displacement curves of pullout testing in (a) 20 PCF (b) 10 PCF groups.

\section{Discussion}

The objective of this study was to perform FEA and mechanical tests to validate a distinctive $\mathrm{Mg}$ alloy-based suture anchor design. In the numerical analysis, pullout tests involving analogous boundary conditions were used to investigate the stress distribution and predominant geometrical factors related to pullout strength, which represents the suture anchors used for fixation, offering immediate stability. Moreover, a previously reported optimal design composed of Mg-Zn-Ca bulk metallic glass, developed by Cheng et al., was manufactured using computer numerical control machining [31].

Studies have employed FEA to investigate the interplay between stress distribution and thread factors (e.g., thread shape, thread pitch, face angle, thread depth, and thread width) for suture anchor designs composed of titanium alloys or stainless steel; however, none of the previous studies have conducted the same investigation for Mg-based materi- 
als $[11,26]$. Such thread-related characteristics may have a considerable influence on the stress distribution of materials because the thread geometry can change the force types on the bone-to-implant surface. Compressive force has been reported to benefit osseointegration by increasing the bone density, but tensile stress is regarded as a weakening factor in bone [32]. The primary aim of the FEA in this study was to attain a reasonable balance between compressive and tensile forces while avoiding a critical concentration of von Mises stress; the secondary aim was to estimate the pullout strength of the optimal design by calculating the reaction force under displacement control.

Related studies have evaluated various thread shapes for suture anchors, including V-shaped, square, buttress, and reverse buttress threads; these diverse threads change the types and directions of forces at the bone-to-implant interface. A pullout test in this study revealed that a reverse buttress thread exhibited the greatest pullout strength and lowest stress of all thread types; thus, this thread shape was employed in this study. Thread angle, which is a factor influencing the stress distribution of dental thread implants, was defined as a two-option parameter $\left(23^{\circ}\right.$ or $\left.45^{\circ}\right)$ in this study (Figure 2 (LA)). The results indicate that samples with sharper threads generated a higher stress value in the normal bone group (Table 4); this can be attributed to stress concentration due to the apical thread geometry and different contact area. This finding is consistent with observations in a related study [33].

One unique feature of the proposed suture anchor design is the tapered head (Figure 2 (TA)), which was inspired by locking screws. During pullout, the axial force provides a normal component to the taper's surface and generates excessive friction to resist the removal. Our FEA results reveal that the pullout strength decreased as the tapered angle increased, indicating that sharper tapers have an adverse effect on pullout resistance (Tables 2 and 3).

We observed that the width of the suture groove had the least effect on both stress value and pullout strength; this finding suggests that the groove design, in terms of structural stability, might be ignored in certain geometries. However, the groove design in suture anchors is mostly related to the strength of the suture itself, which was not examined in our FEA study.

Inspired by microthreads in dental implant studies, we also investigated relevant stress values in the upper thread. Microthreads, with the same outer diameter as the thread in the cylindrical part, have been proposed for providing stress distribution and bone support because they enable a greater contact area on the cortical-to-implant surface. The pitches of the microthreads were 0.8 and $0.7 \mathrm{~mm}$ (Figure 2 (UP)), with reference to the optimal value reported by Kong et al., and the contact areas of the cortical-to-implant surface in the conical part were 22.8 and $25.02 \mathrm{~mm}^{2}$ [34]. However, the dimension and morphologies of our suture anchor design and dental cylindrical implant differed considerably; thus, the effects of the aforementioned reference values were considered in two levels for simplification in this study. The lower stress value on both the suture anchor and upper bone stress was observed in the $0.7 \mathrm{~mm}$ group (Tables 4-7); this level also exhibited the higher pullout strength in the displacement-controlled simulation (Tables 2 and 3), which indicated that the smaller microthread pitch was preferred in this case.

The main purpose of rotator cuff repair is to attach injured soft tissue to the bone surface and to provide sufficient stability against the cyclic loading of anchor removal during mobilization for enhanced tissue healing. Relevant studies have examined other factors involved in rotator cuff repair failure, such as fixation strength, suture methods, bone quality, and implant location. We proposed a suture anchor design with favorable stress distribution and acceptable numerical analysis results; in vivo biomechanical tests are necessary to examine the complete functions of this suture anchor design in rotator cuff repair. This study has some limitations. First, the difference between in vitro testing and real-world suture anchor usage should be noted. Simple assumptions, including axial upward removal loading and material properties, such as Poisson's ratio, the constant which we assigned to the materials was based on the assumption that all materials were 
isotropic, can limit the complexity of FEA; as a trade-off, this simplification fails to provide sufficient evaluation in the living tissue environment in terms of osseointegration and physiological reactions. Furthermore, the mechanical properties of Mg-based metallic glass, a novel material, differed to some extent from those used in this FEA.

In this study, the main differences between the two types of test blocks were density and Young's modulus. As the density decreased, the total volume of the test block that could withstand the pullout force of the suture anchor also decreased, which resulted in the suture anchor being released more easily. The low Young's modulus, indicating a higher likelihood of material yielding, is another factor that contributed to the marked difference in pullout strength between the 10- and 20-PCF groups. Notably, in both the mechanical tests and FEA, the ratio of the pullout strength of the 20-PCF group to that of the 10-PCF group was approximately 4 , although there was ignorable deviation between pullout strengths measured in two methods, indicating that our FEA can provide a reliable prediction of the mechanical behavior of the suture anchor. For two testing methods, the strength in the osteoporotic bone was compared with testing in normal bone as the control group. The main purpose of this study was to assess the effects of various combinations of distinctive parameters through FEA. The parametrical comparison of simulation results might optimize the fixation strength of the new anchor in its future clinical application. Further studies will compare with conventional anchors made of titanium and biocomposite materials to understand the influence of different materials.

Researchers have indicated the importance of bone mass regeneration in rotator cuff repair [35]. Second, loading conditions applied in mechanical tests cannot represent realworld loading conditions. Because of shoulder joint motions and the arrangement of tendons, an upward axial removal force appears to be desirable; thus, this procedure is regarded as a standard approach for testing suture anchors. Various loading angles should be considered in future studies. Third, a single loading condition in this study provided solid evidence for evaluating the primary stability of our design; however, suitable loading values and modes should be continually applied to the suture anchor fixation to evaluate the failure mode of this design. Certain loading conditions in suture anchor usage or eyelet designs would cause both suture breakage and anchor deformation. Moreover, to enhance the experimental control and reduce the cost of the FEA in this study, only two to three levels were selected for each parameter. This simplification may have resulted in an inadequate investigation of the structural effects. Consider, for example, the pitch of the microthreads; 0.8 or $0.7 \mathrm{~mm}$ might not be the optimal choice under such suture anchor dimensions. Additional investigations of each parameter in wider ranges are necessary to obtain a clearer understanding of this special suture anchor design.

Mg-based alloys, which exhibit excellent biodegradability and biocompatability, have become a highly popular material for use in biomaterials. Several studies have used such alloys for bone implants [36,37]. In this study, the typical material properties of $\mathrm{Mg}$ (e.g., a modulus of $45 \mathrm{GPa}$ ) were leveraged in the suture anchor to simplify the simulation. Among a combination of various metals and treatments, Mg-based alloys would exhibit distinct material properties. According to Dunham et al., the mean yield strength for the humerus was 4.4 MPa. This study revealed that the stress in the 20-PCF group ranged from 5.7 to $5.9 \mathrm{MPa}$, signifying that the bone might yield during the pullout, which might negatively influence the growth of bone tissues [38]. From a biomechanical perspective, a smaller Young's modulus in an anchor reduces the interface stress of neighboring bone. Along with the rapid development of $\mathrm{Mg}$ alloys in the medical field, more favorable mechanical properties are likely to be achieved through the combination of new alloy designs, heat treatment, plastic deformation techniques, and dual-phase materials [39]. We suggest that the Young's modulus of newly developed Mg-based alloys should be less than $45 \mathrm{GPa}$ to avoid the interruption of bone growth. The use of biodegradable $\mathrm{Mg}$ and the favorable mechanical structure of the proposed anchor may enable higher stability for shoulder reconstruction. However, several areas such as the eyelet and the edge of thread, where stress is concentrated, should be strengthened to avoid yield or breakage. Toward the aim 
of improving the clinical results of joint reconstruction, the current findings may serve as a reference for combining appropriate materials and enhanced mechanical structure.

Author Contributions: Conceptualization, H.-H.C., H.-Y.T., J.S.-C.J., C.-H.C. and T.-Y.S.; methodology, H.-H.C. and T.-Y.S.; software, T.-Y.S.; validation, H.-Y.T. and T.-Y.S.; formal analysis, T.-Y.S.; investigation, J.S.-C.J., C.-H.C., H.-Y.T. and T.-Y.S.; resources, J.S.-C.J., C.-H.C. and H.-H.C.; data curation, T.-Y.S.; writing-original draft preparation, H.-Y.T. and T.-Y.S.; writing-review and editing, J.S.-C.J., C.-H.C., H.-H.C. and T.-Y.S.; visualization, T.-Y.S.; supervision, J.S.-C.J., C.-H.C. and H.-H.C.; project administration, J.S.-C.J., C.-H.C. and H.-H.C.; funding acquisition, J.S.-C.J., C.-H.C., H.-H.C. and H.-Y.T. All authors have read and agreed to the published version of the manuscript.

Funding: This research was funded by the Ministry of Science and Technology of Taiwan (MOST 106-3114-E-038-001- \& 107-2218-E-038-002- \& 108-2218-E-038-001-).

Data Availability Statement: The data of this research are available to the public in the Open Science Framework at https:/ / osf.io/mgnbu/files/ (accessed on 11 October 2021).

Conflicts of Interest: The authors declare no conflict of interest.

\section{References}

1. Park, M.C.; Cadet, E.R.; Levine, W.N.; Bigliani, L.U.; Ahmad, C.S. Tendon-to-Bone Pressure Distributions at a Repaired Rotator Cuff Footprint Using Transosseous Suture and Suture Anchor Fixation Techniques. Am. J. Sports Med. 2005, 33, 1154-1159. [CrossRef]

2. Cummins, C.A.; Appleyard, R.C.; Strickland, S.; Haen, P.-S.; Chen, S.; Murrell, G.A. Rotator Cuff Repair: An Ex Vivo Analysis of Suture Anchor Repair Techniques on Initial Load to Failure. Arthrosc. J. Arthrosc. Relat. Surg. 2005, 21, 1236-1241. [CrossRef]

3. Liporace, F.A.; Bono, C.M.; Caruso, S.A.; Weiner, B.; Penny, K.; Feldman, A.J.; Grossman, M.G.; Haher, T.R. The Mechanical Effects of Suture Anchor Insertion Angle for Rotator Cuff Repair. Orthopedics 2002, 25, 399-402. [CrossRef] [PubMed]

4. Packer, N.; Calvert, P.; Bayley, J.; Kessel, L. Operative treatment of chronic ruptures of the rotator cuff of the shoulder. J. Bone Jt. Surgery. Br. Vol. 1983, 65, 171-175. [CrossRef]

5. Gartsman, G.M.; Khan, M.; Hammerman, S.M. Arthroscopic Repair of Full-Thickness Tears of the Rotator Cuff. J. Bone Jt. Surg. Am. 1998, 80, 832-840. [CrossRef] [PubMed]

6. Cummins, C.A.; Murrell, G.A. Mode of failure for rotator cuff repair with suture anchors identified at revision surgery. J. Shoulder Elb. Surg. 2003, 12, 128-133. [CrossRef] [PubMed]

7. Bardana, D.D.; Burks, R.T.; West, J.R.; Greis, P.E. The effect of suture anchor design and orientation on suture abrasion: An in vitro study. Arthrosc. J. Arthrosc. Relat. Surg. 2003, 19, 274-281. [CrossRef] [PubMed]

8. Galatz, L.M.; Ball, C.M.; Teefey, S.A.; Middleton, W.D.; Yamaguchi, K. The Outcome and Repair Integrity of Completely Arthroscopically Repaired Large and Massive Rotator Cuff Tears. J. Bone Jt. Surg. Am. 2004, 86, 219-224. [CrossRef] [PubMed]

9. Gazielly, D.F.; Gleyze, P.; Montagnon, C. Functional and Anatomical Results After Rotator Cuff Repair. Clin. Orthop. Relat. Res. 1994, 304, 43-53. [CrossRef]

10. Harryman, D.T.; Mack, L.A.; Wang, K.Y.; Jackins, S.E.; Richardson, M.L.; Matsen, F.A. Repairs of the rotator cuff. Correlation of functional results with integrity of the cuff. J. Bone Jt. Surg. Am. 1991, 73, 982-989. [CrossRef]

11. Chae, S.-W.; Kang, J.-Y.; Lee, J.; Han, S.-H.; Kim, S.-Y. Effect of structural design on the pullout strength of suture anchors for rotator cuff repair. J. Orthop. Res. 2018, 36, 3318-3327. [CrossRef] [PubMed]

12. Sano, H.; Takahashi, A.; Chiba, D.; Hatta, T.; Yamamoto, N.; Itoi, E. Stress distribution inside bone after suture anchor insertion: Simulation using a three-dimensional finite element method. Knee Surg. Sports Traumatol. Arthrosc. 2012, 21, 1777-17822. [CrossRef]

13. Hung, C.-C.; Chen, W.-C.; Yang, C.-T.; Cheng, C.-K.; Chen, C.-H.; Lai, Y.-S. Interference screw versus Endoscrew fixation for anterior cruciate ligament reconstruction: A biomechanical comparative study in sawbones and porcine knees. J. Orthop. Transl. 2014, 2, 82-90. [CrossRef]

14. Ricci, W.M.; Tornetta, P.; Petteys, T.; Gerlach, D.; Cartner, J.; Walker, Z.; Russell, T.A. A Comparison of Screw Insertion Torque and Pullout Strength. J. Orthop. Trauma 2010, 24, 374-378. [CrossRef] [PubMed]

15. Joffre, T.; Isaksson, P.; Procter, P.; Persson, C. Trabecular deformations during screw pull-out: A micro-CT study of lapine bone. Biomech. Model. Mechanobiol. 2017, 16, 1349-1359. [CrossRef] [PubMed]

16. Woo, S.L.-Y.; Debski, R.E.; Vangura, A.J.; Withrow, J.D.; Vogrin, T.M.; Wong, E.K.; Fu, F.H. Use of robotic technology to study the biomechanics of ligaments and their replacements. Oper. Tech. Orthop. 2000, 10, 87-91. [CrossRef]

17. Tuoheti, Y.; Itoi, E.; Yamamoto, N.; Seki, N.; Abe, H.; Minagawa, H.; Okada, K.; Shimada, Y. Contact Area, Contact Pressure, and Pressure Patterns of the Tendon-Bone Interface after Rotator Cuff Repair. Am. J. Sports Med. 2005, 33, 1869-1874. [CrossRef]

18. Yashwant, A.V.; Dilip, S.; Krishnaraj, R.; Ravi, K. Does Change in Thread Shape Influence the Pull Out Strength of Mini Implants? An In vitro Study. J. Clin. Diagn. Res. 2017, 11, ZC17-ZC20. [CrossRef] [PubMed] 
19. Orlando, B.; Barone, A.; Giorno, T.M.; Giacomelli, L.; Tonelli, P.; Covani, U. Insertion torque in different bone models with different screw pitch: An in vitro study. Int. J. Oral Maxillofac. Implant. 2010, 25, 883-887.

20. Barber, F.A.; Herbert, M.A.; Beavis, R.C.; Oro, F.B. Suture Anchor Materials, Eyelets, and Designs: Update 2008. Arthrosc. J. Arthrosc. Relat. Surg. 2008, 24, 859-867. [CrossRef]

21. Visscher, L.E.; Jeffery, C.; Gilmour, T.; Anderson, L.; Couzens, G. The history of suture anchors in orthopaedic surgery. Clin. Biomech. 2019, 61, 70-78. [CrossRef]

22. Kim, J.-H.; Kim, Y.-S.; Park, I.; Lee, H.-J.; Han, S.-Y.; Jung, S.; Shin, S.-J. A Comparison of Open-Construct PEEK Suture Anchor and Non-Vented Biocomposite Suture Anchor in Arthroscopic Rotator Cuff Repair: A Prospective Randomized Clinical Trial. Arthrosc. J. Arthrosc. Relat. Surg. 2020, 36, 389-396. [CrossRef] [PubMed]

23. DeJong, L.E.; DeBerardino, L.T.M.; Brooks, D.E.; Judson, K. In vivo comparison of a metal versus a biodegradable suture anchor. Arthrosc. J. Arthrosc. Relat. Surg. 2004, 20, 511-516. [CrossRef]

24. Wang, J.; Xu, J.; Hopkins, C.; Chow, D.H.; Qin, L. Biodegradable Magnesium-Based Implants in Orthopedics-A General Review and Perspectives. Adv. Sci. 2020, 7, 1902443. [CrossRef]

25. Du, Z.; Yu, X.; Nie, B.; Zhu, Z.; Ibrahim, M.; Yang, K.; Tan, L.; Wang, Y. Effects of magnesium coating on bone-implant interfaces with and without polyether-ether-ketone particle interference: A rabbit model based on porous Ti6Al4V implants. J. Biomed. Mater. Res. Part B Appl. Biomater. 2019, 107, 2388-2396. [CrossRef]

26. Costantino, M.; Schuster, A.; Helmholz, H.; Meyer-Rachner, A.; Willumeit-Römer, R.; Luthringer-Feyerabend, B. Inflammatory response to magnesium-based biodegradable implant materials. Acta Biomater. 2020, 101, 598-608. [CrossRef] [PubMed]

27. Er, M.S.; Altinel, L.; Eroglu, M.; Verim, O.; Demir, T.; Atmaca, H. Suture anchor fixation strength with or without augmentation in osteopenic and severely osteoporotic bones in rotator cuff repair: A biomechanical study on polyurethane foam model. J. Orthop. Surg. Res. 2014, 9, 48. [CrossRef]

28. Hibbeler, R.C. Mechanics of Materials; Pearson Education: Upper Saddle River, NJ, USA, 2003.

29. Liu, S.; Qi, W.; Zhang, Y.; Wu, Z.-X.; Yan, Y.-B.; Lei, W. Effect of bone material properties on effective region in screw-bone model: An experimental and finite element study. Biomed. Eng. Online 2014, 13, 83. [CrossRef]

30. ASTM International. ASTM F 543. Standard Specification and Test Methods for Metallic Medical Bone Screws; ASTM International: West Conshohocken, PA, USA, 2017; Volume 1.

31. Wong, P.-C.; Tsai, P.-H.; Li, T.-H.; Cheng, C.-K.; Jang, J.; Huang, J.C.C. Degradation behavior and mechanical strength of Mg-Zn-Ca bulk metallic glass composites with Ti particles as biodegradable materials. J. Alloys Compd. 2017, 699, 914-920. [CrossRef]

32. Dunham, C.E.; Takaki, S.E.; Johnson, J.A.; Dunning, C.E. Mechanical properties of cancellous bone of the distal humerus. Clin. Biomech. 2005, 20, 834-838. [CrossRef] [PubMed]

33. El-Anwar, M.I.; Osman, W. Finite Element Study On Arthroscopic Anchor Design Aspects. Open Access Maced. J. Med. Sci. 2019, 7, 628-631. [CrossRef]

34. Kong, L.; Liu, B.; Hu, K.-J.; Li, D.-H.; Song, Y.-L.; Ma, P.; Yang, J. Optimized thread pitch design and stress analysis of the cylinder screwed dental implant. Hua Xi Kou Qiang Yi Xue Za Zhi West China J. Stomatol. 2006, 24, 509-512.

35. Kim, D.-G.; Kim, K.-H.; Jo, Y.; Lee, J.Y.; Park, Y.J.; Chung, C.P.; Seol, Y.-J.; Han, J.-S. Bone regeneration into side openings and hollow inner channel of a dental implant. J. Mech. Behav. Biomed. Mater. 2020, 101, 103416. [CrossRef] [PubMed]

36. Geng, J.P.; Ma, Q.S.; Xu, W.; Tan, K.B.C.; Liu, G. Finite element analysis of four thread-form configurations in a stepped screw implant. J. Oral Rehabil. 2004, 31, 233-239. [CrossRef]

37. Razavi, M.; Huang, Y. Assessment of magnesium-based biomaterials: From bench to clinic. Biomater. Sci. 2019, 7, $2241-2263$. [CrossRef] [PubMed]

38. Prasadh, S.; Ratheesh, V.; Manakari, V.; Parande, G.; Gupta, M.; Wong, R. The Potential of Magnesium Based Materials in Mandibular Reconstruction. Metals 2019, 9, 302. [CrossRef]

39. Takano-Yamamoto, T. Osteocyte function under compressive mechanical force. Jpn. Dent. Sci. Rev. 2014, 50, 29-39. [CrossRef] 